Article

\title{
Fashion Trendsetting, Creative Traits and Behaviors, and Pro-Environmental Behaviors: Comparing Korean and U.S. College Students
}

\author{
Jane Workman ${ }^{1}$, Seung-Hee Lee ${ }^{1}$ and Kwangho Jung ${ }^{2, *}$ \\ 1 Fashion Design and Merchandising, 311 Quigley Hall, Southern Illinois University, Carbondale, IL 62901, \\ USA; jworkman@siu.edu (J.W.); shlee@siu.edu (S.-H.L.) \\ 2 Korea Institute of Public Affairs, Graduate School of Public Administration, Seoul National University, \\ 1 Gwanak-ro, Gwanak-gu, Seoul 08826, Korea \\ * Correspondence: kwjung77@snu.ac.kr or kwjung77@gmail.com; Tel.: +82-02-880-5626
}

Received: 26 August 2017; Accepted: 23 October 2017; Published: 30 October 2017

\begin{abstract}
According to Hofstede's theory of cultural dimensions, cultures differ in cultural values and norms; values and norms that may influence differences in trendsetting, creative traits, and behaviors, and pro-environmental behaviors. Further, because men and women have been socialized within particular cultures, gender differences may exist in trendsetting, creative traits and behaviors, and pro-environmental behaviors. Trendsetters have characteristics that are interrelated with creative traits and behaviors, perhaps inclining them to endorse pro-environmental behaviors. However, the interrelationships among these variables remain unexplored. Thus, the purpose of this study was to examine these three variables among college students in South Korea and the United States (U.S.), specifically looking at cultural and gender differences. Participants were 225 Korean college students and 221 U.S. college students. Questionnaires included demographic items and scales measuring trendsetting, creative traits and behaviors, and pro-environmental behaviors. Data analyses included descriptive statistics, Cronbach's alpha reliability, MANOVA, ANOVA, and SNK posthoc test. Results show that U.S. (vs. Korean) students indicated greater trendsetting and creative traits and behaviors but not greater pro-environmental behaviors. Fashion trendsetting groups in both Korea and the U.S. differed in creative traits and behaviors and pro-environmental behaviors. Among Korean trendsetting groups, reluctant adopters scored lowest on creative traits and behaviors and pro-environmental behaviors. Among U.S. trendsetting groups, trendsetters the scored highest on creative traits and behaviors and pro-environmental behaviors; reluctant adopters scored lowest on pro-environmental behaviors. Theoretical and practical implications are provided for researchers and marketers.
\end{abstract}

Keywords: fashion trendsetting; creativity; pro-environmental behaviors; gender; Korea; U.S.

\section{Introduction}

Globalization links countries, markets, and societies around the world. Creativity and pro-environmental behaviors are essential to address environmental problems and promote sustainability worldwide. However, fundamental questions remain unanswered: which consumers are among the first to adopt creative innovations, and which consumers possess pro-environmental attitudes? One group of consumers, that is, fashion trendsetters can be projected to play a role in developing creative ecological communities $[1,2]$ by helping to increase the likelihood that community members will pursue pro-environmental activities [3]. Because fashion trendsetters actively use social media (i.e., fashion blogs, Facebook, Instagram, Pinterest, Twitter, etc.) to disseminate their fashion preferences and influence others [4-6], trendsetters may be persuaded to extend their influence by 
making known their preferences for pro-environmental behaviors. College students in the United States (U.S.) and South Korea are advanced in adoption of social media, for example, $67 \%$ of Internet users in the U.S. and South Korea use social networking sites [7,8], not only to share information but to search for information about particular topics [9].

Individuals vary in time of adoption of innovative products (such as fashion) and ideas (such as pro-environmental attitudes). Various groups accept and implement innovative products and ideas at different times: a trendsetting group that leads innovation adoption, groups that adopt innovations sooner or later, and a group that is resistant to adoption of innovations. Creative traits and pro-environmental attitudes will affect the process of innovation adoption and diffusion. Because trendsetters have characteristics that are interrelated with creative traits and behaviors, the trendsetting group seems likely to participate in more pro-environmental behaviors than groups that adopt later or resist adopting innovations. However, no research has analyzed the relationships among trendsetting, creative traits and behaviors, and pro-environmental behaviors. Understanding the relationships among these variables within the younger generation will provide guidance for overcoming environmental issues in the future. Analysis of similarities and differences in these variables in different countries may provide information about how pro-environmental behaviors can be encouraged in the future.

This study compares male and female Korean and U.S. college students in fashion trendsetting, creative traits and behaviors, and pro-environmental behaviors. The purpose of this study was to examine these three variables among college students in South Korea and the United States, specifically looking at cultural and gender differences. First, the literature on fashion trendsetting, creativity, and pro-environmental behaviors is summarized and hypotheses are proposed. Second, measures, data, and analysis methods are provided for variables used in the study. Third, results of empirical analyses are presented for verification of 12 research hypotheses. Finally, the key points of this study are summarized and discussed. In addition, theoretical and practical implications of this study are discussed and further research projects are suggested.

\section{Relevant Literature Review and Theoretical Framework}

An individual's traits and behaviors are shaped by gender roles and cultural norms. In most societies, boys and girls are socialized differently and are encouraged to pursue gender appropriate activities [10]. Hofstede's theory of cultural dimensions [11] proposes that cultures differ in cultural values and norms; differences that may influence differences in innovation adoption, creative traits and behaviors, and pro-environmental behaviors between members of different cultures. For example, trendsetters (i.e., those who are the earliest to adopt an innovation) are socialized to think in culturally traditional ways that can affect acceptance or rejection of innovations [12]. Further, individuals from individualist and egalitarian cultures may develop more creative traits and behaviors than individuals from collectivist and hierarchical cultures [13]. Appreciation of variety and a future orientation are psychological motivations for environmentally friendly behaviors [14]. Cultures with a future orientation and a concern for quality of life may display more pro-environmental behaviors.

According to Hofstede's [11] theory of cultural dimensions, individuals socialized in different cultures differ in the endorsement of six broad cultural values. Values are "the ideas one considers important in life; an individual's set of principles for behavior" [15] (p. 431). Hofstede's six cultural dimensions are [16]: individualism (Korea-18; U.S.-91), indulgence (Korea-29, U.S.—68), long-term orientation (Korea-100; U.S.—26), masculinity (Korea-39; U.S. -62), power distance (Korea-60; U.S.-40), and uncertainty avoidance (Korea-85; U.S.—46).

When compared with the U.S., Korea ranks lower in individualism, indulgence, and masculinity but higher in long-term orientation, power distance, and uncertainty avoidance. Hofstede's theory of cultural dimensions [16] was used as a framework to help explain the role of culture in U.S. and Korean students' trendsetting, creative traits and behaviors, and pro-environmental behaviors. 


\subsection{Trendsetting and Innovation Adoption}

Rogers' adoption-diffusion model depicts a normal distribution curve, illustrating consumers' adoption of innovations over time [12]. Workman and Lee [13] adapted Rogers' diffusion of innovations model to depict a timeline of fashion adopters: consumer change agents (first 20\%), early adopters (next 30\%), late adopters (next 30\%), and reluctant adopters (final 20\%). The model was tested and found to be a useful framework for studying fashion adoption.

"Trendsetting refers to individuals who are among the first to adopt an innovation and then communicate this effectively to others" [14] (p. 88). An important role for trendsetters (aka consumer change agents) is noticing an innovation's potential early in its life cycle and communicating this potential to others. Trendsetters play an important part in the adoption-diffusion process for new products (i.e., innovations). According to Batinic et al., trendsetters are on the alert for new trends and possess a wide-ranging interest in innovations [14].

"An innovation is an idea, practice, or object perceived as new by an individual" ([12] (p. 12). An individual's reaction to an idea, practice, or object is determined by his or her perception of its newness; it can be labeled an innovation if an individual perceives it as new. Understanding the adoption process for an innovation can be enhanced by understanding the characteristics of the earliest adopters (i.e., trendsetters).

\subsubsection{Trendsetting and Culture}

Chiu and Kwan stated that successful innovation involves three stages: (a) creation of new ideas; (b) choosing, editing, and promoting new ideas; and, (c) acceptance of new ideas by consumers [17] (p. 447). Culture influences all three stages, for example, cultural norms affect the likelihood of an innovation being accepted. An innovative product must be novel and useful, however, a product's novelty is relative to what is common in a culture and its usefulness is relative to needs and wants of prospective users in a culture [18]. Trendsetters are socialized to think in culturally traditional ways that can affect their acceptance or rejection of innovations.

Strict adherence to cultural norms may lead to a rejection of innovative ideas or products. Consumers are highly uncertain concerning innovations that are ground-breaking discoveries and find it easier to adopt an incremental innovation with confidence [17]. High scores on uncertainty avoidance (Korea 85/100) indicate resistance to innovation and intolerance of nontraditional behavior and ideas, while low scores (US 46/100) indicate a tolerance for freedom of expression and a willingness to accept innovative products and new ideas $[11,16,19]$. Trendsetters socialized in an indulgent society may be more willing to accept innovations than trendsetters socialized in a restrained society. Korea $(29 / 100)$ is a restrained society with relatively strong control over impulsive behavior, while the U.S. $(68 / 100)$ is an indulgent society with citizens who anticipate instant gratification from work or leisure activities. Further, when compared with the U.S. (91/100), Korea (18/100) ranks lower in individualism. Trendsetters, at least fashion trendsetters, have a greater need for uniqueness than later adopters [20-22]. Being among the first to adopt an innovation is one method of establishing uniqueness, a value that is important in cultures high in individualism but not in collectivist cultures. Thus, cultural values influence the adoption-decision process [22].

Hypothesis 1 (H1). U.S. students will score higher in trendsetting than Korean students.

\subsubsection{Trendsetting and Gender}

Gender impacts the diffusion of innovations process whether or not researchers analyze it as a variable. Evidence of gender differences in trendsetting is inconsistent [23,24]. Some studies report that women are more likely to be earlier adopters than men ([25-29]. Others find no difference [30,31]. How adoption of innovations is operationally defined may account for some of the inconsistencies in 
results. Some inconsistencies may be due to type of innovation (e.g., fashion, mobile internet, computer technology); however, within any one type of innovation, such as fashion, inconsistencies exist.

Hypothesis 2 (H2). Women will score higher in trendsetting than men.

\subsection{Creative Traits and Behaviors}

Gough defined a creative personality as a collection of separate personality traits related to creativity [32]. Some studies have found that personality traits such as self-confidence, self-efficacy, and broad interests are related to creativity [33-35]. Creative individuals are flexible, able to cope with change, willing to overcome obstacles, take sensible risks, and tolerate ambiguity [36]. Feist (1998) [34] conducted a meta-analysis and found that artists (vs. non-artists) were less cautious, conscientious, controlled, orderly, reliable, conventional, rigid, and socialized. However, they were more aesthetic, creative, curious, imaginative, open to experience, sensitive, and original. Traits and behaviors of creative individuals were summarized as follows: low on socialization-control scales, impulsive, nonconformist, rule-doubting, skeptical, independent, unconcerned with obligations or duties, in search of change, easily bored, autonomous, introverted, self-confident, self-accepting, and ambitious.

\subsubsection{Creative Traits and Behaviors and Culture}

Cultures differ in how much they value individualism and egalitarianism $[11,16,19]$. Korea $(18 / 100)$ is a collectivist society with a self-image characterized as "we", reflecting the interdependence among society's members, while the U.S. $(91 / 100)$ is an individualist society with self-image characterized as "I". Power distance refers to unequal distribution of power. Korea $(60 / 100)$ is a slightly hierarchical society and the U.S. (40/100) is an egalitarian society. Individuals from cultures that are individualist and egalitarian (vs. collectivist and hierarchical) may have more creative traits and behaviors [37]. According to Morris and Leung [38], Western norms consider originality and novelty more important than usefulness and appropriateness; Eastern norms consider usefulness more important than originality.

Hypothesis 3 (H3). U.S. students will score higher in creative traits and behaviors than Korean students.

\subsubsection{Creative Traits and Behaviors and Gender}

Feist [34] found no gender differences in a meta-analysis of creative personality traits. Many studies have found no gender differences in creativity; differences that have been found did not show any consistent pattern [39,40]. According to Abraham [41], females display a slight advantage in creativity over males from preschool through college. Abraham concluded that differences between men and women, in creativity, may reflect gender-dependent strategies or cognitive style when performing creative tasks. According to Baer and Kaufman [40], women tend to score higher on creativity tests than men. Women scored higher than men on Openness to Aesthetics, Feelings, and Actions, while men scored higher than women on Openness to Ideas [42].

Hypothesis 4 (H4). Women will score higher in creative traits and behaviors than men.

\subsubsection{Creative Traits and Behaviors and Trendsetting}

Amabile [43] defined a creative product as novel and appropriate. Sarkar and Chakrabarti [44] declared that a creative product must be original and functional. Individuals with creative traits and behaviors may be primed to look for, and assess the potential of, new ideas, practices, or products [14]. There is no research to support the idea that trendsetters may display creative traits and behaviors to a greater degree than later adopters. However, an important facet of trendsetting is noticing an 
innovation and its potential early in its life cycle, thus, it is logical to predict that, within any particular culture, earlier adopters will score higher in creative traits and behaviors than later adopters.

Hypothesis 5 (H5). Earlier adopters will score higher in creative traits and behaviors than later adopters.

Hypothesis 6 (H6). Among Korean students, earlier adopters will score higher in creative traits and behaviors than later adopters.

Hypothesis 7 (H7). Among U.S. students, earlier adopters will score higher in creative traits and behaviors than later adopters.

\subsection{Pro-Environmental Behaviors}

According to environmental sociologists, a new environmental paradigm emerged among U.S. citizens in the late 1960s and early 1970s [45,46]. This paradigm emphasized limits to growth, belief in a future eco-crisis, belief in the fragility of nature, and a rejection of the idea that humans are the most important element of existence and, thus, are exempt from the laws of nature. Belief in the new environmental paradigm was positively related to pro-environmental behavior $[47,48]$. Corral-Verdugo et al. [49] (p. 34) conceptualized an affinity towards diversity as an "individual predisposition to appreciate the dynamic variety of human-nature interactions in everyday life situations". Appreciation of variety is considered to be a psychological impetus or motivation for pro-environmental behaviors. Corral-Verdugo et al. [49] concluded that affinity toward diversity, along with other psychological variables (e.g., future orientation), was a foundation for a pro-sustainability orientation, which, in turn, predicted pro-environmental behaviors.

\subsubsection{Pro-Environmental Behaviors and Culture}

Cultures differ in cultural values that are important for pro-environmental behaviors, for example, future orientation and masculinity $[11,16,19]$. Low scores on long term orientation (U.S. 26/100) indicate normative societies whose citizens have strong opinions about social issues, an emphasis on quick results, and a suspicious view of societal change, while high scores (Korea 100/100) point to a culture with a future orientation. Further, a high score (U.S. 62/100) on masculinity indicates a society driven by competition, achievement, and success, whereas a low score (Korea 39/100) indicates a society that values caring for others and quality of life. Pro-environmental behaviors may be more prevalent in a society that values a future orientation and quality of life.

Hypothesis 8 (H8). Korean students will score higher in pro-environmental behaviors than U.S. students.

\subsubsection{Pro-Environmental Behaviors and Gender}

Hunter, Hatch, and Johnson [50] used the 1993 International Social Survey to examine gender differences in environmentally-oriented behaviors across 22 nations. Women engaged in more pro-environmental behaviors than men in many nations. Authors concluded that gender differences in pro-environmental behaviors reflected traditional gender socialization such that individual behaviors are shaped by gender expectations and cultural norms. Traditional gender socialization encourages females to take on roles as caregivers and nurturers, to be cooperative and display compassion leading to concern for the maintenance of life and relationships, while males are socialized to be involved in the public sphere. In most societies, boys and girls are socialized differently and encouraged to pursue gendered activities [51]. These general gender roles exist cross-culturally and predispose women to display more environmental concern than men cross-culturally [51]. This gender difference in environmental attitudes and behaviors was supported across 14 countries in Europe, Latin America and the U.S., and was consistently stronger for behaviors than for attitudes [52]. Chen et al. [53] found that females practiced more pro-environmental behaviors than men. Women reported stronger 
environmental attitudes, concern, and behaviors than men (e.g., [54-56]). Women, then, are more likely to engage in pro-environmental behavior due to cultural and social practices.

Hypothesis 9 (H9). Women will score higher in pro-environmental behaviors than men.

\subsubsection{Pro-Environmental Behaviors and Trendsetting}

Trendsetters are the individuals who are among the first to adopt an innovation [14]. Trendsetters have a greater need for variety than later adopters [57]. Trendsetters have a greater future orientation than later adopters [57]. These traits may lead trendsetters to practice more pro-environmental behaviors than later adopters.

Hypothesis 10 (H10). Earlier adopters will score higher in pro-environmental behaviors than later adopters.

\subsubsection{Pro-Environmental Behaviors, Trendsetting, and Culture}

Korean and U.S. students may differ in trendsetting because of cultural values, such as uncertainty avoidance (Korea 85/100; U.S. 46/100). Trendsetters have a future orientation and a future orientation is a strong cultural value in Korea $(100 / 100)$ but a weak value in the U.S. $(26 / 100)$. Therefore, within a culture, in both Korea and the U.S., trendsetting groups will be likely to differ in pro-environmental behaviors.

Hypothesis 11 (H11). Among Korean students, earlier adopters will score higher on pro-environmental behaviors than later adopters.

Hypothesis 12 (H12). Among U.S. students, earlier adopters will score higher in pro-environmental behaviors than later adopters.

\section{Research Method}

\subsection{Survey Instruments}

A questionnaire was compiled that contained demographic items, a 9-item trendsetting questionnaire [14], a 9-item creative traits and behaviors scale [58], and a 13-item pro-environmental behavior scale [49]. In order to conduct a survey in South Korea and the US, first an English version of the questionnaire was developed. The questionnaire was then translated into Korean by experts who were fluent in both English and Korean; then, the questionnaire was back-translated into English and was reviewed by a native English speaker.

\subsubsection{The Trendsetting Questionnaire}

Batinic, Wolff, and Haupt [14] conducted a multiple group confirmatory factor analyses that supported the unidimensionality of the trendsetting questionnaire. Four samples yielded coefficient alphas of 0.85, 0.87, 0.88, and 0.91, indicating an adequate reliability. Batinic, Wolff, and Haupt [14] noted that trendsetting will be more evident in domains of personal interest (e.g., fashion, technological devices). An example of an item from the trendsetting questionnaire as adapted for this study is "I like trying something new in fashion". A Likert-type scale ( $1=$ not true at all; $5=$ completely true $)$ accompanied each item.

\subsubsection{The Creative Traits and Behavior Scale}

To measure creative traits and behaviors, nine items were selected from Factor 5: Creativity and imagination subscales [58]. Goldberg reported reliabilities of 0.81 for the creativity scale and 0.78 for the imagination subscale. Some items were re-worded to reflect a positive direction. Students used a 
5-point rating scale ( 5 = very accurate; 1 = very inaccurate) to indicate how accurately each statement described them in relation to other people of the same sex and age. Examples of traits and behaviors in the scale include doing things that others find strange or unexpected, thinking up new ways of doing things, and being interested in abstract ideas [58].

\subsubsection{The Pro-Environmental Behaviors Scale}

Corral-Verdugo et al. [49] verified the unidimensional structure of the pro-environmental behaviors scale and found reliability of 0.76 in study one and 0.75 in study two. The scale's validity was verified by its positive correlation with an affinity toward diversity and sustainability orientation. Items were accompanied by 5 -point response categories ( $5=$ strongly agree; $1=$ strongly disagree). An example of an item from the pro-environmental behaviors scale is "I bring empty bottles to a recycling bin".

\subsection{Survey Participants}

Participants in this study represent two cultures that vary in cultural values, that is, as compared with the U.S., Korea ranks lower in individualism, indulgence, and masculinity, but higher in long-term orientation, power distance, and uncertainty avoidance. The U.S. at $14 \%$ and Korea at $13 \%$ are similar in percentage of individuals aged 20-29 [59,60]. During the previous 12 months, $71.7 \%$ of U.S. and $83.8 \%$ of Korean individuals had used information and communication technologies [9]. U.S. and Korean college students are very interested in fashion and actively use technology such as social media to broadcast and advocate their preferences and influence others $[7,8]$. Therefore, it is valuable to examine this age group within two cultures as a means to further understand their similarities and differences in characteristics such as trendsetting, creativity, and pro-environmental behaviors.

Participants were 225 Korean college students ( 90 women, 135 men) from a large university in Seoul, South Korea and 221 U.S. college students from a large Midwestern university (112 women, 107 men; 2 missing data). Korean students ranged in age from 18 to 30 (mean age $=23.29$ ); U.S. students ranged in age from 18 to 30 (mean age $=21.36$ ). Class status for Korean students was: year $1(n=39)$; year $2(n=71)$; year $3(n=32)$; year $4(n=42)$; and year $5(n=41)$. Class status for U.S. students was: year $1(n=11)$; year $2(n=23)$; year $3(n=102)$; year $4(n=74)$; and year $5(n=11)$. For Korean students, marital status included: single $(n=216)$ and married $(n=9)$. For U.S. students, marital status included: single $(n=211)$, married $(n=4)$, and otherwise classified $(n=6)$.

\subsection{Survey Procedure and Analysis}

Questionnaires were distributed and collected in large lecture classes. Participants completed the questionnaires in about $20 \mathrm{~min}$. Data were analyzed using descriptive statistics, Cronbach's alpha reliability, MANOVA, ANOVA, and SNK posthoc test.

\section{Empirical Results}

Descriptive statistics and reliability for the trendsetting questionnaire, creative traits and behaviors scale, and pro-environmental behaviors scale are displayed in Table 1. Reliability was acceptable for all scales for both countries. Cronbach's alpha ranged from 0.75 to 0.96 .

$\mathrm{H} 1, \mathrm{H} 2, \mathrm{H} 3, \mathrm{H} 4, \mathrm{H} 8$, and $\mathrm{H} 9$ were tested with a MANOVA, with country and gender as independent variables and trendsetting questionnaire, creative traits and behavior, and pro-environmental behaviors as dependent variables. MANOVA was significant for country $[\mathrm{F}(3,435)=9.87, p<0.000]$ and gender $[\mathrm{F}(3,435)=22.61, p<0.000]$. There was no significant interaction between country and gender on the dependent variables. 
Table 1. Descriptive statistics and reliability for measures.

\begin{tabular}{|c|c|c|c|}
\hline \multicolumn{2}{|c|}{ Participants Mean (SD) } & Observed Range & Cronbach's $\alpha$ Reliability \\
\hline \multicolumn{4}{|c|}{ Trendsetting questionnaire } \\
\hline All 24.11 & $(9.46)$ & $9-45$ & 0.95 \\
\hline US 25.37 & (10.27) & $9-45$ & 0.96 \\
\hline KN 22.87 & $(8.43)$ & $9-44$ & 0.95 \\
\hline \multicolumn{4}{|c|}{ Creative traits and behaviors } \\
\hline All 30.24 & $(6.02)$ & $11-45$ & 0.79 \\
\hline US 32.21 & $(6.10)$ & $11-45$ & 0.81 \\
\hline KN 28.31 & $(5.37)$ & $11-45$ & 0.75 \\
\hline \multicolumn{4}{|c|}{ Pro-environmental behavior } \\
\hline All 40.66 & $(9.80)$ & $13-65$ & 0.85 \\
\hline US 40.45 & $(10.43)$ & $13-65$ & 0.87 \\
\hline KN 40.86 & $(9.13)$ & $13-65$ & 0.85 \\
\hline
\end{tabular}

ANOVA (see Table 2) revealed that men and women differed in trendsetting (H2) and pro-environmental behaviors (H9), but not in creative traits and behavior (H4). Women indicated greater trendsetting and more pro-environmental behaviors than men did.

Table 2. ANOVA results of country and gender on trendsetting, creative traits and behaviors, and pro-environmental behavior.

\begin{tabular}{|c|c|c|c|c|c|}
\hline Scale & Mean (SD) & \multicolumn{2}{|c|}{ d.f.* Mean Square } & $F$ & $p<$ \\
\hline \multicolumn{6}{|c|}{ Trendsetting questionnaire } \\
\hline Country & & 1,437 & 477.55 & 5.71 & 0.000 \\
\hline US & $\mathrm{M}=25.37(\mathrm{SL}$ & 10.27) & & & \\
\hline $\mathrm{KN}$ & $\mathrm{M}=22.90(\mathrm{~S} D$ & 8.49) & & & \\
\hline Gender & & 1,437 & 2072.59 & 24.79 & 0.000 \\
\hline Men & $\mathrm{M}=22.03(\mathrm{SL}$ & 9.31) & & & \\
\hline Women & $\mathrm{M}=26.72(\mathrm{SL}$ & 9.11) & & & \\
\hline \multicolumn{6}{|c|}{ Creative traits and behaviors } \\
\hline Country & & 1,437 & 1631.48 & 49.88 & 0.000 \\
\hline US & $\mathrm{M}=32.21(\mathrm{SL}$ & $6.01)$ & & & \\
\hline $\mathrm{KN}$ & $\mathrm{M}=28.32(\mathrm{SL}$ & $5.39)$ & & & \\
\hline Gender & & 1,437 & 2.02 & 0.06 & 0.80 \\
\hline Men & $\mathrm{M}=29.99$ & 6.12) & & & \\
\hline Women & $\mathrm{M}=30.62(\mathrm{SL}$ & 5.90) & & & \\
\hline \multicolumn{6}{|c|}{ Pro-environmental behavior } \\
\hline Country & & 1,437 & 55.29 & 0.58 & 0.45 \\
\hline US & $\mathrm{M}=40.45(\mathrm{SL}$ & 10.43) & & & \\
\hline $\mathrm{KN}$ & $\mathrm{M}=40.86$ & 9.13) & & & \\
\hline Gender & & 1,437 & 576.78 & 6.06 & 0.01 \\
\hline Men & $\mathrm{M}=39.66$ & 9.80) & & & \\
\hline Women & $\mathrm{M}=41.88$ & 9.67) & & & \\
\hline
\end{tabular}

ANOVA (see Table 2) revealed that Korean and U.S. students differed in trendsetting (H1), and creative traits and behavior (H3), but not pro-environmental behaviors (H8). U.S. (vs. Korean) 
students indicated greater trendsetting and creative traits and behavior. Korean and U.S. students did not differ in pro-environmental behaviors.

Therefore, H1, H2, H3, and $\mathrm{H} 9$ were supported; $\mathrm{H} 4$ and $\mathrm{H} 8$ were not supported.

As specified by Workman and Lee [13], the mean and standard deviation from the trendsetting questionnaire were used to divide participants into four trendsetting groups: $16.33 \%$ trendsetters $(n=72 ; \mathrm{m}=38.50 ; \mathrm{SD}=3.59) ; 33.1 \%$ early adopters $(n=146 ; \mathrm{m}=28.99 ; \mathrm{SD}=2.45) ; 31.52 \%$ late adopters $(n=139 ; \mathrm{m}=19.87 ; \mathrm{SD}=2.80) ;$ and, $19.05 \%$ reluctant adopters $(n=84 ; \mathrm{m}=10.45 ; \mathrm{SD}=1.76)$. To test hypotheses $\mathrm{H} 5$ and H10, MANOVA was conducted, with trendsetting groups as the independent variable and creative traits and behaviors and pro-environmental behaviors as dependent variables. MANOVA was significant for trendsetting $[\mathrm{F}(6,874)=7.35, p<0.000]$. There was no significant interaction between country and gender on the dependent variables.

ANOVA (see Table 3) revealed that trendsetting groups differed in both creative traits and behaviors (H5) and pro-environmental behaviors (H10). The SNK post hoc test showed that trendsetting groups differed significantly $(p<0.05)$ from each other in creative traits and behaviors and pro-environmental behaviors.

Table 3. ANOVA results of trendsetting on creative traits and behaviors and pro-environmental behavior.

\begin{tabular}{|c|c|c|c|c|}
\hline Scale & Mean (SD) & d.f. Mean Square & $F$ & $p<$ \\
\hline \multicolumn{5}{|c|}{ All participants } \\
\hline Creative traits and behavior & & 402.48 & 11.91 & 0.000 \\
\hline Trendsetters & $\mathrm{M}=33.18(6.50)$ & & & \\
\hline Early adopters & $\mathrm{M}=30.12 \mathrm{a}(5.08)$ & & & \\
\hline Late adopters & $\mathrm{M}=30.53 \mathrm{a}(5.90)$ & & & \\
\hline Reluctant adopters & $M=27.63(6.22)$ & & & \\
\hline Pro-environmental behavior & & 776.38 & 8.51 & 0.000 \\
\hline Trendsetters & $\mathrm{M}=44.03(11.62)$ & & & \\
\hline Early adopters & $\mathrm{M}=40.72 \mathrm{a}(8.79)$ & & & \\
\hline Late adopters & $\mathrm{M}=41.35^{\mathrm{a}}(8.90)$ & & & \\
\hline Reluctant adopters & $\mathrm{M}=36.51(9.92)$ & & & \\
\hline \multicolumn{5}{|c|}{ US participants } \\
\hline Creative traits and behavior & & 258.27 & 7.79 & 0.000 \\
\hline Trendsetters & $\mathrm{M}=35.58 \mathrm{a}(5.26)$ & & & \\
\hline Early adopters & $\mathrm{M}=31.93 \mathrm{~b}(5.75)$ & & & \\
\hline Late adopters & $\mathrm{M}=32.18^{\mathrm{b}}(5.69$ & & & \\
\hline Reluctant adopters & $M=29.59 b(6.24)$ & & & \\
\hline Pro-environmental behavior & & 362.74 & 3.44 & 0.018 \\
\hline Trendsetters & $\mathrm{M}=44.35 \mathrm{a}(12.17)$ & & & \\
\hline Early adopters & $\mathrm{M}=40.53^{\mathrm{a}, \mathrm{b}}(10.23$ & & & \\
\hline Late adopters & $\mathrm{M}=39.89 \mathrm{a}, \mathrm{b}(9.17)$ & & & \\
\hline Reluctant adopters & $\mathrm{M}=37.28^{\mathrm{b}}(9.90)$ & & & \\
\hline \multicolumn{5}{|c|}{ Korean participants } \\
\hline Creative traits and behavior & & 3,218 & 3.10 & 0.028 \\
\hline Trendsetters & $\mathrm{M}=29.69 \mathrm{a}(6.05)$ & & & \\
\hline Early adopters & $\mathrm{M}=28.49 \mathrm{a}(4.59)$ & & & \\
\hline Late adopters & $\mathrm{M}=28.97 \mathrm{a}(5.30)$ & & & \\
\hline Reluctant adopters & $\mathrm{M}=26.32^{\mathrm{b}}(6.09)$ & & & \\
\hline Pro-environmental behavior & & 375.56 & 4.73 & 0.003 \\
\hline Trendsetters & $\mathrm{M}=42.97 \mathrm{a}(10.08)$ & & & \\
\hline Early adopters & $\mathrm{M}=41.27 \mathrm{a}(8.77)$ & & & \\
\hline Late adopters & $\mathrm{M}=42.43^{\mathrm{a}}(7.43)$ & & & \\
\hline Reluctant adopters & $\mathrm{M}=36.53 \mathrm{~b}(9.99)$ & & & \\
\hline
\end{tabular}

Note: Means sharing the same superscript $\left({ }^{\mathrm{a}}\right.$ or $\left.{ }^{\mathrm{b}}\right)$ did not differ significantly from each other. 
Because Korean and U.S. students were found to differ significantly in trendsetting, the Korean mean and standard deviation from the trendsetting questionnaire were used to divide Korean participants into four trendsetting groups: $16.22 \%$ trendsetters $(n=36 ; \mathrm{m}=35.33 ; \mathrm{SD}=2.86) ; 27.48 \%$ early adopters $(n=61 ; \mathrm{m}=26.96 ; \mathrm{SD}=2.52) ; 36.94 \%$ late adopters $(n=82 ; \mathrm{m}=19.12 ; \mathrm{SD}=2.18)$; and, $19.37 \%$ reluctant adopters $(n=43 ; \mathrm{m}=10.28$; SD $=1.61)$. To test H6 and H11, MANOVA was conducted with Korean trendsetting groups as the independent variable and creative traits and behavior and pro-environmental behaviors as dependent variables. MANOVA was significant for trendsetting $[\mathrm{F}(6,436)=2.78, p<0.012]$. There was no significant interaction between country and gender on the dependent variables.

ANOVA (see Table 3) revealed that Korean trendsetting groups differed in creative traits and behaviors and pro-environmental behavior. The SNK post hoc test showed that trendsetting groups differed significantly $(p<0.05)$ from each other in creative traits and behavior $(\mathrm{H} 6)$ and pro-environmental behaviors (H11). Reluctant adopters scored lowest on creative traits and behaviors and pro-environmental behaviors. Reluctant adopters differed significantly from all of the other trendsetting groups who did not differ significantly from one another.

Because Korean and U.S. students were found to differ significantly in trendsetting, the U.S. mean and standard deviation from the trendsetting questionnaire were used to divide U.S. participants into four trendsetting groups: $18.26 \%$ trendsetters $(n=40 ; \mathrm{m}=40.38$; $\mathrm{SD}=3.29) ; 32.88 \%$ early adopters $(n=72 ; \mathrm{m}=30.25 ; \mathrm{SD}=2.61) ; 27.85 \%$ late adopters $(n=61 ; \mathrm{m}=20.56 ; \mathrm{SD}=3.09) ;$ and, $21.0 \%$ reluctant adopters $(n=46 ; \mathrm{m}=11.11 ; \mathrm{SD}=2.26)$. To test $\mathrm{H} 7$ and H12, MANOVA was conducted with U.S. trendsetting groups as the independent variable and creative traits and behaviors and pro-environmental behaviors as dependent variables. MANOVA was significant for trendsetting $[\mathrm{F}(6,430)=4.06, p<0.000]$. ANOVA (see Table 3) revealed that U.S. trendsetting groups differed in creative traits and behaviors, and pro-environmental behaviors. The SNK post hoc test showed that trendsetting groups differed significantly $(p<0.05)$ from each other in creative traits and behaviors $(\mathrm{H} 7)$ and pro-environmental behaviors (H12). Trendsetters scored highest on creative traits and behaviors and differed significantly from all of the other trendsetting groups who did not differ significantly from one another in creative traits and behaviors. Trendsetters also scored highest on pro-environmental behaviors but they did not differ significantly in pro-environmental behaviors from early and late adopters. Reluctant adopters scored lowest on pro-environmental behaviors but they did not differ significantly in pro-environmental behaviors from early and late adopters.

Therefore, H5, H6, H7, H10, H11, and H12 were supported.

\section{Discussion and Implications}

Based on Hofstede's theory of cultural dimensions, differences were predicted between U.S. and Korean students' trendsetting, creative traits and behaviors, and pro-environmental behaviors. Further, because men and women have been socialized within particular cultures, gender differences were predicted in trendsetting, creative traits and behaviors, and pro-environmental behaviors. Because trendsetters have characteristics that are linked to creative traits and behaviors and might make them more likely to endorse pro-environmental behaviors, differences were predicted among trendsetting groups in creative traits and behaviors and pro-environmental behaviors. Ten out of 12 hypotheses predicting cultural, gender, and trendsetting differences were supported.

\subsection{Summary of Results and Discussion}

Reliability was acceptable for all scales for both countries. U.S. (vs. Korean) students indicated greater trendsetting and creative traits and behaviors, but not greater pro-environmental behaviors. Women, as compared to men, indicated greater trendsetting and more pro-environmental behaviors, but equivalent creative traits and behaviors. Trendsetting groups differed in both creative traits and behaviors and pro-environmental behaviors. Korean trendsetting groups differed in creative traits and behaviors, and pro-environmental behaviors; reluctant adopters scored lowest on creative 
traits and behaviors and pro-environmental behaviors. U.S. trendsetting groups differed in creative traits and behaviors, and pro-environmental behaviors; trendsetters scored highest on creative traits and behaviors and pro-environmental behaviors; and, reluctant adopters scored lowest on pro-environmental behaviors.

Based on Hofstede's theory of cultural dimensions, future orientation and femininity (values in Korean culture) were expected to result in more pro-environmental behaviors among Korean participants than U.S. participants (socialized in a culture lower in future orientation and high in masculinity). However, Korean and U.S. participants did not differ in pro-environmental behaviors that might be attributed to the new environmental paradigm that emerged among U.S. citizens in the late 1960s and early 1970s [50,51,53]. Environmentalism is a social issue about which U.S. citizens have strong opinions (a characteristic associated with low scores on long term orientation). Regarding trendsetters practicing more pro-environmental behaviors, trendsetters have a greater future orientation than later adopters [57], which is consistent with concern for quality of life. Trendsetters also have a greater need for variety than later adopters [57], a need that may extend beyond the domain of fashion to a general appreciation for variety, including variety in environmental elements, such as animals and plants.

This study showed that earlier adopters had more creative traits and behaviors and engaged in more pro-environmental behaviors than later adopters, indicating a possible link between creativity and pro-environmental behaviors. Identifying solutions to environmental problems depends on creative ideas as well as ecological knowledge. Creativity may affect the degree to which pro-environmental messages and behaviors emerge [61]. Trencher et al. [62] conceptualized 'sustainability co-creation' to encourage sustainability activities as a means of transforming society. Tran and Park [63] proposed a co-creative framework for redesigning a product service system. Findings from the current study support Chen et al.'s [64] idea of a relationship between creativity and environmentally friendly innovations and between creativity and proactive environmental management.

Within the U.S. and Korea, gender affected pro-environmental behaviors. When compared with men, women were more likely to engage in pro-environmental behavior. According to Hunter et al. [50], because of gender-role socialization, women are more aware of the connections between causes and consequences of damage to the environment.

\subsection{Theoretical Implications}

Results confirm the influence of culture on U.S. and Korean college students' trendsetting and creative traits and behaviors. Hofstede's theory of cultural dimensions offered insight into differences between Korean and U.S. students regarding trendsetting, creative traits and behaviors and pro-environmental behaviors. Support was found for 10 of 12 hypotheses formulated on cultural differences in the values of individualism, indulgence, masculinity, long-term orientation, power distance, and uncertainty avoidance. No previous research has explored the relationship among these three variables. These findings can contribute to research using Hofstede's theory to investigate cultural differences.

The trendsetting theory [14] regards trendsetting as a dispositional construct. Korean and U.S. participants differed in trendsetting; however, regardless of culture, trendsetters differed from later adopters in creative traits and behaviors and pro-environmental behaviors. The trendsetting questionnaire, which has not previously been tested in Korea, showed nominological validity within both U.S. and Korean cultures.

Workman and Lee's model [13] of fashion adoption worked well to identify trendsetters. The percentage of participants found in each group was similar to the proposed model. Overall, the model produced $16.33 \%$ trendsetters, $33.1 \%$ early adopters, $31.52 \%$ late adopters, and $19.05 \%$ reluctant adopters. The slight variations from the proposed 20\%/30\%/30\%/20\% conceptual model can be explained by individual variation in participants. Additionally, Workman and Lee found that, among U.S. college student participants, the model was slightly skewed toward early (vs. late) adopters. 
Among Korean participants, there were $16.22 \%$ trendsetters, $27.48 \%$ early adopters, $36.94 \%$ late adopters, and $19.37 \%$ reluctant adopters. Among U.S. participants, there were $18.26 \%$ trendsetters, $32.88 \%$ early adopters, $27.85 \%$ late adopters, and $21.0 \%$ reluctant adopters. Among Korean college student participants, the model was slightly skewed toward late (vs. early) adopters. There were fewer trendsetters and early adopters among Korean participants than among U.S. participants, which can be attributed to cultural differences in uncertainty avoidance and individualism. This was the first time to test the model with participants from a culture other than the U.S. Testing within other cultures will verify if the model can be applied cross-culturally with confidence.

\subsection{Practical Implications}

These results are beneficial for international fashion retailers or marketers to understand trendsetting and gender differences in young consumers within a cultural setting. Trendsetters play an important role in the fashion adoption-diffusion process. The traits and behaviors of trendsetters, within a cultural setting, are powerful influences in regard to innovation adoption. Trendsetters act as gatekeepers (i.e., individuals who control access to innovations) for other potential end-users. Trendsetters either accept or reject an innovation and then the diffusion process begins or stagnates. Even though trendsetters may have grown up and been socialized to think in culturally traditional ways (e.g., collectivism, uncertainty avoidance), their personal traits and behaviors interact with cultural values in their reaction to innovations. Therefore, identifying and targeting trendsetters within a particular culture would be a wise course of action for international marketers and retailers of new products.

A powerful promotional tool that can be useful to marketers is word-of-mouth including social network systems (SNS) because SNS include trendsetters. Among fashion consumers, trendsetters have greater influence than other groups. Promotional techniques targeted to fashion trendsetters might be successful regardless of culture because trendsetters in both cultures shared common traits (i.e., creative traits and behaviors). Businesses may want to target fashion trendsetters via social media, as women (who are more likely to be fashion trendsetters) are more likely to use social media than men in both the U.S. and Korea [7,8]. Fashion trendsetters can use their influence to spread not only fashion information, but also information about pro-environmental behaviors, to other members of their social network.

\subsection{Limitations and Further Research}

This study was limited to data from Korean and U.S. college students. A survey of the general population would provide a more complete picture of innovation adoption, creative traits and behaviors, and pro-environmental behaviors. Further research is recommended to examine other countries with regard to cultural differences in innovation adoption, creative traits and behaviors, and pro-environmental behavior. Using a scale to measure individual endorsement of cultural values (e.g., [16]) would provide insight into the relative power of cultural values and individual values. Workman and Lee's fashion adoption model [13] would be strengthened by testing it with other types of innovative products, for example, technological devices or mobile phones. According to Batinic, Wolff, and Haupt [14], trendsetting will more readily manifest itself in domains of personal interest. Therefore, individuals who were not trendsetters in the current study (which measured fashion trendsetting) might be trendsetters in a study that measured, for example, mobile internet trendsetting. Recent innovative concepts, such as ecopreneurship, ecopreneurs, and sustainable entrepreneurship, illustrate how environmental issues can be progressively integrated into entrepreneurship [62-64], but the links among them are unclear, especially in terms of institutional and cultural contexts across various countries. Trendsetters, as compared to later adopters, are likely candidates to provide creative thinking to environmental challenges facing business, industry, and civic sectors. In addition, further research on whether or not trendsetters are risk-takers when making purchase decisions is valuable to understand brand relationships and risk [65]. Further study is also useful to identify any 
unrevealed relationships between trendsetters and brand phenomena, including brand awareness, brand attachment, brand trust, brand love, and brand loyalty $[65,66]$.

Recent fashion trendsetting studies [13,17] can facilitate interdisciplinary research among various areas, including open innovation, educational curriculum, and development of business models for artistic and cultural enterprises. For instance, the current research that found a relationship between fashion trendsetting and pro-environmental behaviors can be linked to emerging research topics, including how architectural trendsetters create imaginative architectural knowledge [67] or how trendsetters in various fields affect the dynamics from open innovation to evolutionary change [68]. Further research can also explore how business trendsetters develop novel business models for arts and cultural organizations [69], and how educational trendsetters can lead in creating innovative educational curriculum [70]. This interdisciplinary approach is expected to integrate knowledge frames among various fields such as fashion diffusion model, trendsetting model, open innovation principles, and architectural literacy.

Author Contributions: Jane Workman, Seung-Hee Lee and Kwangho Jung conceived and designed the survey; Seung-Hee Lee and Kwangho Jung collected data; Jane Workman, Kwangho Jung and Seung-Hee Lee analyzed the data; Jane Workman wrote the first draft of the paper; Seung-Hee Lee and Kwangho Jung contributed to the paper's subsequent drafts.

Conflicts of Interest: The authors declare no conflict of interest.

\section{References}

1. Ratten, V. Entrepreneurship, Innovation and Smart Cities; Taylor \& Francis: New York, NY, USA, 2017.

2. Russ, A.; Peters, S.; Krasny, M.; Stedman, R. Development of ecological place meaning in New York City. J. Environ. Educ. 2015, 46, 73-93. [CrossRef]

3. Glaeser, E. Triumph of the City: How Our Greatest Invention Makes Us Richer, Smarter, Greener, Healthier, and Happier; Penguin: London, UK, 2011.

4. Casaló, L.V.; Flavián, C.; Ibáñez, S. Antecedents and consequences of fashion opinion leadership in Instagram. In Proceedings of the 2017 Global Fashion Management Conference at Vienna, Vienna, Austria, 6-9 July 2017; pp. 5-6.

5. Chun, E.; Ko, E. The role of fashion leaders on the fashion social platform: Implications of knowledge sharing in the Korean fashion industry. In Proceedings of the 2014 Global Marketing Conference at Singapore, Singapore, 15-18 July 2014; pp. 1696-1698.

6. Wolny, J.; Mueller, C. Analysis of fashion consumers' motives to engage in electronic word-of-mouth communication through social media platforms. J. Mark. Manag. 2013, 29, 562-583. [CrossRef]

7. Duggan, M.; Brenner, J. The Demographics of Social Media Users-2012. Available online: http://pewinternet. org/Reports/2013/Social-media-users.aspx (accessed on 26 August 2017).

8. Korea Communications Commission \& Korea Internet \& Security Agency. 2012 Survey on Internet Usage: Executive Summary. Available online: http:/ /isis.kisa.or.kr/board/index.jsp?pageId=040100\&bbsId=7\& itemId=788\&pageIndex=1 (accessed on 26 August 2017).

9. Oh, S.; Kim, S. College Students' Use of Social Media for Health in the USA and Korea. Information Research, 19, Paper 643. 2014. Available online: http:/ InformationR.net/ir/19-4/paper643.html (accessed on 26 August 2017).

10. Williams, J.E.; Best, D.L. Measuring Sex Stereotypes: A Multination Study; Sage Publications, Inc.: Newbury Park, CA, USA, 1990.

11. Hofstede, G. Culture's Consequences: Comparing Values, Behaviors, Institutions and Organizations across Nations; Sage: Newbury Park, CA, USA, 2001.

12. Rogers, E.M. Diffusion of Innovations, 5th ed.; Free Press: New York, NY, USA, 2003.

13. Workman, J.E.; Lee, S.H. What do we know about fashion adoption groups? A proposal and test of a model of fashion adoption. Int. J. Consum. Stud. 2017, 41, 61-69. [CrossRef]

14. Batinic, B.; Wolff, H.; Haupt, C. Construction and factorial structure of a short version of the trendsetting questionnaire (TDS-K). A cross-validation using multigroup confirmatory factor analyses. Eur. J. Psychol. Assess. 2008, 24, 88-94. [CrossRef] 
15. Rath, P.; Bay, S.; Petrizzi, R.; Gill, P. The Why of the Buy: Consumer Behavior and Fashion Marketing, 2nd ed.; Fairchild: New York, NY, USA, 2015.

16. Itim International. Geert Hofstede Cultural Dimensions. 2017. Available online: http://www.geert-hofstede. com (accessed on 26 August 2017).

17. Chiu, C.Y.; Kwan, L.Y.Y. Culture and creativity: A process model. Manag. Organ. Rev. 2010, 6, 447-461. [CrossRef]

18. Ward, T.B.; Patterson, M.J.; Sifonis, C.M.; Dodds, R.A.; Saunders, K. The role of graded category structure in imaginative thought. Mem. Cognit. 2002, 30, 199-216. [CrossRef] [PubMed]

19. Hofstede, G.; Hofstede, G.J.; Minkov, M. Cultures and Organizations: Software of the Mind, 3rd ed.; McGraw-Hill: New York, NY, USA, 2010.

20. Workman, J.E.; Caldwell, L.F. Centrality of visual product aesthetics, tactile and uniqueness needs of fashion consumers. Int. J. Consum. Stud. 2007, 31, 589-596. [CrossRef]

21. Workman, J.E.; Kidd, L.K. Use of the need for uniqueness scale to characterize fashion consumer groups. Cloth. Text. Res. J. 2000, 18, 227-236. [CrossRef]

22. Steenkamp, J.B.E.; Hofstede, F.T.; Wedel, M. A cross-national investigation into the individual and national cultural antecedents of consumer innovativeness. J. Mark. 1999, 63, 55-69. [CrossRef]

23. Ilie, V.; Van Slyke, C.; Green, G.; Hao, L. Gender differences in perceptions and use of communication technologies: A diffusion of innovation approach. Inf. Resour. Manag. J. 2005, 18, 13. [CrossRef]

24. Mazman, S.G.; Usluel, Y.K.; Çevik, V. Social Influence in the Adoption Process and Usage of Innovation: Gender Differences. Available online: http://waset.org/publications/11887/social-influence-in-theadoption-process-and-usage-of-innovation-gender-differences (accessed on 24 October 2017).

25. Bertrandias, L.; Goldsmith, R.E. Some psychological motivations for fashion opinion leadership and fashion opinion seeking. J. Fash. Mark. Manag. 2006, 10, 25-40. [CrossRef]

26. Cho, S.; Workman, J. Gender, fashion innovativeness and opinion leadership, and need for touch: Effects on multi-channel choice and touch/non-touch preference in clothing shopping. J. Fash. Mark. Manag. 2011, 15, 363-382. [CrossRef]

27. Goldsmith, R.E.; Clark, R.A. An analysis of factors affecting fashion opinion leadership and fashion opinion seeking. J. Fash. Mark. Manag. 2008, 12, 308-322. [CrossRef]

28. Quigley, C.J., Jr.; Notarantonio, E.M. A cross-cultural comparison of United States and Austrian fashion consumers. J. Euromark. 2009, 8, 233-244. [CrossRef]

29. Workman, J.E.; Cho, S. Gender, fashion consumer groups, and shopping orientation. Fam. Consum. Sci. Res. J. 2012, 40, 267-283. [CrossRef]

30. Batinic, B.; Haupt, C.; Wieselhuber, J. Validity and norms for a questionnaire to assess trendsetting (TDS). Diagnostica 2006, 52, 60-72. [CrossRef]

31. Cardoso, P.R.; Costa, H.S.; Novais, L.A. Fashion consumer profiles in the Portuguese market: Involvement, innovativeness, self-expression and impulsiveness as segmentation criteria. Int. J. Consum. Stud. 2010, 34, 638-647. [CrossRef]

32. Gough, H.G. A creative personality scale for the adjective check list. J. Personal. Soc. Psychol. 1979, 37, 1398-1405. [CrossRef]

33. Barron, F.; Harrington, D.M. Creativity, intelligence, and personality. Annu. Rev. Psychol. 1981, 32, 439-476. [CrossRef]

34. Feist, G.J. A meta-analysis of personality in scientific and artistic creativity. Personal. Soc. Psychol. Rev. 1998, 2, 290-309. [CrossRef] [PubMed]

35. Sternberg, R.J. The nature of creativity. Creat. Res. J. 2006, 18, 87-98. [CrossRef]

36. Runco, M.A. Creativity. Annu. Rev. Psychol. 2004, 55, 657-687. [CrossRef] [PubMed]

37. De Dreu, C.K. Human creativity: Reflections on the role of culture. Manag. Organ. Rev. 2010, 6, 437-446. [CrossRef]

38. Morris, M.W.; Leung, K. Creativity East and West: Perspectives and parallels. Manag. Organ. Rev. 2010, 6, 313-327. [CrossRef]

39. Baer, J.; Kaufman, J.C. Creativity Research in English-Speaking Countries; Cambridge University Press: New York, NY, USA, 2006.

40. Baer, J.; Kaufman, J.C. Gender differences in creativity. J. Creat. Behav. 2008, 42, 75-105. [CrossRef] 
41. Abraham, A. Gender and creativity: An overview of psychological and neuroscientific literature. Brain Imaging Behav. 2016, 10, 609-618. [CrossRef] [PubMed]

42. Costa, P.T., Jr.; Terracciano, A.; McCrae, R.R. Gender differences in personality traits across cultures: Robust and surprising findings. J. Personal. Soc. Psychol. 2001, 81, 322-331. [CrossRef] [PubMed]

43. Amabile, T.M. The Social Psychology of Creativity; Springer: New York, NY, USA, 1983.

44. Sarkar, P.; Chakrabarti, A. Assessing design creativity. Des. Stud. 2011, 32, 348-383. [CrossRef]

45. Catton, W.R.; Dunlap, R.E. Environmental sociology: New paradigm. Am. Sociol. 1978, 13, 41-49.

46. Catton, W.R.; Dunlap, R.E. Paradigms, theories, and primacy of Hep-Nep distinction. Am. Sociol. 1978, 13, 256-259.

47. Dunlap, R.E.; Van Liere, K.D.; Mertig, A.G.; Jones, R.E. Measuring endorsement of the new ecological paradigm: A revised NEP scale. J. Soc. Issues 2000, 56, 425-442. [CrossRef]

48. Buttel, F.H. New directions in environmental sociology. Annu. Rev. Sociol. 1987, 13, 465-488. [CrossRef]

49. Corral-Verdugo, V.; Bonnes, M.; Tapia-Fonllem, C.; Fraijo-Sing, B.; Frías-Armenta, M.; Carrus, G. Correlates of pro-sustainability orientation: The affinity towards diversity. J. Environ. Psychol. 2009, 29, 34-43. [CrossRef]

50. Hunter, L.M.; Hatch, A.; Johnson, A. Cross-national gender variation in environmental behaviors. Soc. Sci. Q. 2004, 85, 677-694. [CrossRef]

51. Zelezny, L.C.; Chua, P.; Aldrich, C. New ways of thinking about environmentalism: Elaborating on gender differences in environmentalism. J. Soc. Issues 2000, 56, 443-457. [CrossRef]

52. Gifford, R.; Nilsson, A. Personal and social factors that influence pro-environmental concern and behaviour: A review. Int. J. Psychol. 2014, 49, 141-157. [CrossRef] [PubMed]

53. Chen, X.; Peterson, M.N.; Hull, V.; Lu, C.; Lee, G.D.; Hong, D.; Liu, J. Effects of attitudinal and sociodemographic factors on pro-environmental behaviour in urban China. Environ. Conserv. 2011. [CrossRef]

54. Luchs, M.G.; Mooradian, T.A. Sex, personality, and sustainable consumer behaviour: Elucidating the gender effect. J. Consum. Policy 2012, 35, 127-144. [CrossRef]

55. Scannell, L.; Gifford, R. Personally relevant climate change: The role of place attachment and local versus global message framing in engagement. Environ. Behav. 2013, 45, 60-85. [CrossRef]

56. Workman, J.E.; Johnson, K.K.P. Fashion opinion leadership, fashion innovativeness, and need for variety. Cloth. Text. Res. J. 1993, 11, 60-64. [CrossRef]

57. Lee, S.H.; Workman, J.; Jung, K. Perception of time, creative attitudes, and adoption of innovations: A cross-cultural study from Chinese and US college students. Sustainability 2016, 8, 1193. [CrossRef]

58. Goldberg, L.R. A broad-bandwidth, public domain, personality inventory measuring the lower-level facets of several five-factor models. Personal. Psychol. Eur. 1999, 7, 7-28.

59. United States Census Bureau. Age and Sex Composition in the United States: 2012. Available online: https:/ / www.census.gov/data/tables/2012/demo/age-and-sex/2012-age-sex-composition.html (accessed on 26 August 2017).

60. South Korea. The Ratio of the Aged 20-29 of the Whole Population in 2013 Is Approximately $12.88 \%$. This Population Data Is Based on Population Statistics Based on Resident Registration of the Ministry of the Interior and Safety (MOIS). Available online: http:/ / mois.go.kr/frt/sub/a05/totStat/screen.do (accessed on 23 October 2017).

61. Tsetse, D.; De Groot, W.T. Opportunity and Problem in Context (OPiC): A Framework for Environmental Management. Sustainability 2009, 1, 19-34. [CrossRef]

62. Trencher, G.; Nagao, M.; Chen, C.; Ichiki, K.; Sadayoshi, T.; Kinai, M.; Kamitani, M.; Nakamura, S.; Yamauchi, A.; Yarime, M. Implementing Sustainability Co-Creation between Universities and Society: A Typology-Based Understanding. Sustainability 2007, 9, 594. [CrossRef]

63. Tran, T.; Park, J.Y. Development of a Novel Co-Creative Framework for Redesigning Product Service Systems. Sustainability 2016, 8, 434. [CrossRef]

64. Chen, Y.S.; Chang, T.W.; Lin, C.Y.; Lai, P.Y.; Wang, K.H. The Influence of Proactive Green Innovation and Reactive Green Innovation on Green Product Development Performance: The Mediation Role of Green Creativity. Sustainability 2016, 8, 966. [CrossRef]

65. Lee, S.H.; Workman, J.E.; Jung, K. Brand relationships and risk: Influence of risk avoidance and gender on brand consumption. J. Open Innov. Technol. Mark. Complex. 2016, 2, 14. [CrossRef]

66. Lee, S.H.; Workman, J.E. Compulsive buying and branding phenomena. J. Open Innov. Technol. Mark. Complex. 2015, 1, 3. [CrossRef] 
67. Han, J. Exploitation of architectural knowledge and innovation. J. Open Innov. Technol. Mark. Complex. 2017, 3, 15. [CrossRef]

68. Yun, J.J.; Won, D.; Park, K. Dynamics from open innovation to evolutionary change. J. Open Innov. Technol. Mark. Complex. 2016, 2, 7. [CrossRef]

69. Schiuma, G.; Lerro, A. The business model prism: Managing and innovating business models of arts and cultural organisations. J. Open Innov. Technol. Mark. Complex. 2017, 3, 13. [CrossRef]

70. Kim, S.; Ryoo, H.; Ahn, H. Student customized creative education model based on open innovation. J. Open Innov. Technol. Mark. Complex. 2017, 3, 6. [CrossRef]

(C) 2017 by the authors. Licensee MDPI, Basel, Switzerland. This article is an open access article distributed under the terms and conditions of the Creative Commons Attribution (CC BY) license (http:/ / creativecommons.org/licenses/by/4.0/). 